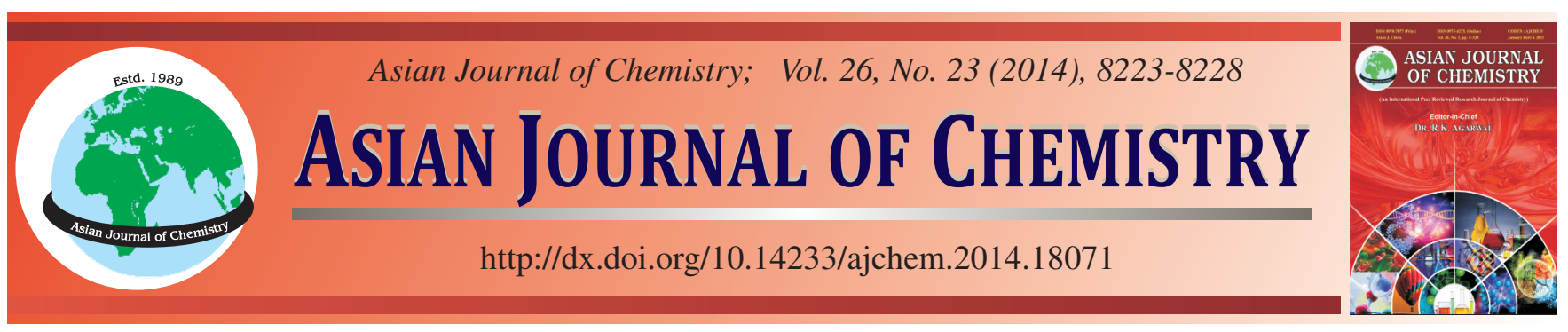

\title{
Preparation of High Porous Poly(2-ethylhexyl methacrylate-co-ethylene Glycol Dimethacrylate) Monolithic Columns for Fast Separation of Small Molecules
}

\author{
Hessa K. Al-Shammari ${ }^{1}$, Ahmad Aqel ${ }^{2}$ and Zeid A. Alothman ${ }^{2, *}$
}

${ }^{1}$ Chemistry Department, College of Science, University of Ha'il, P.O. Box 1560, Ha'il, Kingdom of Saudi Arabia

${ }^{2}$ Advanced Materials Research Chair, Chemistry Department, College of Science, King Saud University, P.O. Box 2455, Riyadh 11451, Kingdom of Saudi Arabia

*Corresponding author: Fax: +96 614675989; Tel: +96 614675999; E-mail: zaothman@ksu.edu.sa

\begin{abstract}
This paper describes the fabrication of monolithic materials for use as stationary phases in capillary liquid chromatography. Four columns were synthesized in the confines of $320 \mu \mathrm{m}$ i.d. and $200 \mathrm{~mm}$ long fused-silica capillaries using a single step in situ copolymerization of 2-ethylhexyl methacrylate and ethylene glycol dimethacrylate (EDMA). The polymerization procedure was optimized; ethylene glycol dimethacrylate crosslinker content showed predominant influence on the columns characteristics. Changes of the porous and hydrodynamic properties of the prepared monolithic columns were thoroughly investigated and their morphologies were characterized by examining the scanning electron microscopy images and Fourier transform infrared spectra. A decrease in the porogen to monomer ratio corresponded to smaller microglobules and a lower total porosity. The microglobules had an approximate diameter in the range of 1-2 $\mu \mathrm{m}$. The total porosities ranged from 73 to $80 \%$ using the retention times of uracil as an unretained marker. The resulting monoliths exhibited good permeability and mechanical stability, while swelling behaviour was observed and discussed. The efficiency and performance towards different sets of analytes were obtained; mixtures of aromatic hydrocarbons and phenolic compounds were successfully separated and evaluated. Fast separations were achieved in less than $5 \mathrm{~min}$ for the model compounds.
\end{abstract}

Keywords: Capillary liquid chromatography, Monolithic column, 2-Ethylhexyl methacrylate, Aromatic hydrocarbons, Phenolic compounds.

\section{INTRODUCTION}

Capillary liquid chromatography has been one of the most important recent developments in separation and analysis technology. Capillary liquid chromatography offers several advantages over conventional normal chromatography. The advantages include increased chromatographic resolution, higher efficiency, lower sample and solvent consumption, the ability to analyze and isolate rare compounds of interest, greater mass sensitivity and ease of on-line connection to a mass spectrometer ${ }^{1-3}$. Traditionally, capillary liquid chromatography uses fused silica capillaries prepared with a variety of stationary phases. This technique appears to be very promising for separating a wide variety of analytes for different applications ${ }^{4-10}$. However, the successful development of this technique is closely related to the technical challenges associated with manufacturing the column.

Monolithic columns have quickly become extremely popular and they have attracted increasing interest as separation media for all chromatographic methods. The unique structure of the monoliths and their ease of preparation offer improved chromatographic performance and favorable properties that result in high efficiency ${ }^{11-14}$. Hjertén et al. ${ }^{15}$ first introduced the use of monoliths with capillary liquid chromatography in 1989 and since that time, monolithic stationary phases have been extensively studied for use in capillary liquid chromatography ${ }^{16-20}$. In addition to the preparation conditions, such as the reaction time and temperature, the chemical and physical properties of the monolithic polymer depend on the type and concentrations of the monomer, crosslinker, porogenic solvent and initiator.

Several monoliths, including methacrylate polymers ${ }^{21-30}$, have been widely prepared and studied in the literature. There are several advantages associated with using methacrylatebased polymers as monolithic stationary phases, such as high stability in a wide range of mobile phase $\mathrm{pH}$ values (2-12), fast and simple preparation and ease of functionalization. Methacrylate monolithic columns also have various selectivities towards monomers with wide ranging polarities ${ }^{31,32}$.

\section{EXPERIMENTAL}

Formic acid, toluene, aminophenol, chlorotoluene and nitrotoluene of analytical grade were purchased from $\mathrm{BDH}$ 
(England). Cresol and chlorophenol were provided by Merck (Schuchardt, Germany).

HPLC grade acetonitrile was purchased from BDH (England). The purified water used throughout all experiments was prepared using a Milli-Q system (Advantage with Elix, Millipore S.A.S. 67120 Molsheim, France) then filtered through a $0.2 \mu \mathrm{m}$ nylon membrane filter (Whatman, England). The mixed mobile phases were always filtered using a vacuum glass filtration system through the same nylon membrane filters and degassed ultrasonically for $30 \mathrm{~min}$ before use.

Fused silica tubing ( $0.32 \mathrm{~mm}$ i.d.) was purchased from Restek (USA). The chemicals used for preparing the monolithic materials in this work were purchased from Aldrich (Steinheim, Germany) and they are as follows: 3-(trimethoxysilyl)propyl methacrylate (TMSM), $98 \%$, ethylene glycol dimethacrylate (EDMA) $98 \%$ used as a crosslinker, 2ethylhexyl methacrylate $98 \%$ as monomer and 2,2'-azobisisobutyronitrile (AIBN) used as a thermal initiator. Toluene, hydrochloric acid, sodium hydroxide, 1-propanol and 1,4butandiol were acquired from BDH (England). All chemicals were used without further purification.

Preparation of capillary monolithic columns: To clean and activate the inner capillary surface, the fused-silica tubing (0.32 mm i.d.) was first rinsed with a $1 \mathrm{M} \mathrm{NaOH}$ solution for $10 \mathrm{~min}$ and then placed in the same solution for $4 \mathrm{~h}$. The capillary was then rinsed with water and air-dried for $10 \mathrm{~min}$ and each step was repeated twice. The tubing was then flushed with $1 \mathrm{M} \mathrm{HCl}$ for $30 \mathrm{~min}$ and air-dried for $5 \mathrm{~min}$. After this step, the capillary was rinsed with toluene for 10 min then flushed with a $20 \%$ of 3-(trimethoxysilyl)propyl methacrylate solution in toluene for $10 \mathrm{~min}$ and then placed in the same solution for $4 \mathrm{~h}$. Then, the capillary was rinsed with toluene for $10 \mathrm{~min}$ and air-dried for $5 \mathrm{~min}$. The activated capillary was then cut into four pieces (200 mm length each) with a razor blade. In this study, a series of monoliths with different compositions of the polymerization mixtures were prepared $(\% \mathrm{v} / \mathrm{v})$ and described in Table- 1 .

\begin{tabular}{ccccc}
\multicolumn{5}{c}{ TABLE-1 } \\
COMPOSITION OF THE POLYMERIZATION MIXTURES \\
USED TO PREPARE THE CAPILLARY \\
MONOLITHIC COLUMNS, (v/v \%) \\
\hline Column & Monomer (\%) & EDMA (\%) & Porogen $(\%)$ & AIBN $(\%)$ \\
\hline $\mathrm{C}_{1}$ & 14 & 14 & 71 & 1 \\
$\mathrm{C}_{2}$ & 12 & 12 & 75 & 1 \\
$\mathrm{C}_{3}$ & 12 & 15 & 72 & 1 \\
$\mathrm{C}_{4}$ & 15 & 12 & 72 & 1 \\
\hline Ethylene glycol dimethacrylate (EDMA); 2 2'-Azobisisobutyronitrile
\end{tabular}

Ethylene glycol dimethacrylate (EDMA); 2,2'-Azobisisobutyronitrile (AIBN)

Four 2-ethylhexyl methacrylate monolithic columns were formed from the copolymerization with ethylene glycol dimethacrylate as a crosslinker in the presence of AIBN as an initiator and a mixture of binary porogenic solvents, including 1-propanol and 1,4-butanediol (65:35, v/v \%). The monoliths were prepared in $320 \mu \mathrm{m}$ i.d. and $200 \mathrm{~mm}$ long capillaries. The polymerization process was performed at $60^{\circ} \mathrm{C}$ for $15 \mathrm{~h}$. The monomer and porogen mixtures were prepared (v/v \%) as described in Table- 1 .
The monomer mixture and the porogen solvents were mixed into a homogenous solution and then sonicated and purged with helium gas for $5 \mathrm{~min}$. Each capillary column was then filled with the corresponding reactant solution and both ends were plugged with a piece of rubber. After the polymerization, the seals were removed. The resulting columns were connected to a HPLC pump and thoroughly washed with acetonitrile to remove the unreacted materials and the porogenic solvents.

Porosity and bed permeability: The total column porosity $\left(\varepsilon_{\mathrm{T}}\right)$ is an important parameter for evaluating the column. Various methods are available to measure the $\varepsilon_{\mathrm{T}}$, such as the flow method ${ }^{43}$ the conductivity method ${ }^{44}$ and the gravimetric method $^{45}$. In this study, the flow method was used to evaluate the $\varepsilon_{\mathrm{T}}$. This method is based on determining the retention volume of an unretained marker (uracil was used in this work) and the geometrical volume of the empty column (because it can be considered as a long cylindrical tube), after correcting for extra-column volume contributions, depending on the tubes used for connection.

The permeability $\left(\mathrm{K}^{0}\right)$ of a porous medium is a measure of its capacity to transmit a fluid driven by an imposed pressure drop across the column. Darcy's law relates the solvent viscosity, pressure drop ${ }^{46}$ and $\varepsilon_{\mathrm{T}}$ to $\mathrm{K}^{0}$. Furthermore, the Hagen-Poiseuille equation ${ }^{47}$ gives the pressure drop in a fluid flowing through a long cylindrical pipe. This physical law has been used to calculate the average diameter of monolith channels, R (macropores). The average velocity of the mobile phase over the channel section $(v)$ is obtained by integrating the momentum transport equation that is derived from the Navier-Stokes equation.

Characterization of monolithic columns: After the chromatographic experiments were finished, the monolith rods in the tubes were washed, cut into small pieces and then dried. The dried columns and the monolith materials were characterized using scanning electron microscope and FT-IR spectroscopy. The pore properties and the microscopic morphology of the polymers were characterized using a Jeol (JSM-6380LA) analytical scanning electron microscope (Japan) at $5 \mathrm{kV}$.

The FT-IR spectra were recorded on a Thermo Nicolet 6700 FT-IR spectrophotometer (USA). The porous monolith was removed from the vial and then crushed. The powder was immersed in $1 \mathrm{~mL}$ of $(50: 50, \mathrm{v} / \mathrm{v})$ acetonitrile/water and shaken for $10 \mathrm{~min}$ to remove any soluble compounds; these processes were repeated twice. After vacuum drying, the monolith powder was thoroughly mixed with $\mathrm{KBr}$ in an approximate ratio of 1:20 and pressed into a pellet. The FT-IR spectrum was then recorded at a resolution of $4 \mathrm{~cm}^{-1}$ over the full mid-IR range (4000-400 $\left.\mathrm{cm}^{-1}\right)$.

HPLC modification and conditions: All analyses were performed with a Shimadzu HPLC system (Kyoto, Japan) that included a pump (LC-6A), a Rheodyne 7125 manual injector, a UV detector (SPD-6A) and a C-R6A integrator. The detector was set to different wavelengths based on the analyzed compounds. Acetonitrile/water solutions with or without acid additives at different ratios were used as a mobile phase. All solutions were filtered through a $0.2 \mu \mathrm{m}$ nylon membrane filter (Whatman, England) before use. All experiments were conducted at room temperature. 
The HPLC system was successfully modified to use microcolumns. The detector was equipped with a $320 \mu \mathrm{m}$ i.d. and $1.6 \mu \mathrm{L}$ volume homemade cell that had a $2 \mathrm{~cm}$ path length. A simple system was constructed for splitting both the mobile phase flow and injection volume and was controlled using a custom-built adjustable flow splitter based on a T-derivation piece connected between the injector and the column. In this configuration, both the column and split flows could be adjusted by changing the inner diameter or length of the splitting PEEK tubing (Varian, USA). In the present work, the selected splitting ratio was 1:200 and the actual injection volume was fixed at $5 \mathrm{~nL}$.

\section{RESULTS AND DISCUSSION}

Preparation of monolithic columns: Four monolithic columns with different monomer, crosslinker and porogen percentage compositions were prepared and they are summarized in Table-1. The columns were prepared according to the procedure described, which includes four steps: (a) activation of the fused silica capillary inner wall, (b) filling the tubing with the monomer mixture, (c) polymerization of the functional monomer and crosslinker at the surface of the column and (d) connecting the column to the HPLC system and washing it with acetonitrile.

Characterization of monolithic columns: The monolithic bed properties and morphology are considered to be key factors that affect the separation capabilities of the capillary column. Monoliths are prepared using bulk polymerization and their structure is defined by the monomer composition and polymerization conditions without further processing ${ }^{33-35}$. Therefore, it is important to investigate and control the parameters of the monoliths during the synthesis.
Columns porosity and permeability: The total porosities of the examined monoliths $\mathrm{C}_{1}, \mathrm{C}_{2}, \mathrm{C}_{3}$ and $\mathrm{C}_{4}$ were $75,80,73$ and $76 \%$, respectively (Table-2). These results were calculated from the retention times of uracil injected through the four columns. These results confirm that, as mentioned in previous works, increasing the porogen ratio in the polymerization mixture corresponds to a decrease of the monomer content and induces a higher porosity of the monolith ${ }^{36-38}$. The porosity values were calculated after extra volume $(8.8 \mu \mathrm{L})$ corrections.

\section{TABLE-2}

PORE CHARACTERISTICS OF THE MONOLITHIC COLUMNS; $\varepsilon_{\mathrm{T}}, \mathrm{K}^{0}$ AND R USING ACETONITRILE AND WATER AS ELUENTS

\begin{tabular}{|c|c|c|c|c|c|}
\hline Column & $\varepsilon_{\mathrm{T}}$ & $\begin{array}{c}\mathrm{K}^{0} \text { using } \\
\text { acetonitrile }\left(\mathrm{m}^{2}\right)\end{array}$ & $\begin{array}{c}\mathrm{K}^{0} \text { using } \\
\text { water }\left(\mathrm{m}^{2}\right)\end{array}$ & $\begin{array}{c}\mathrm{R}(\mu \mathrm{m}) \text { using } \\
\text { acetonitrile }\end{array}$ & $\begin{array}{c}\mathrm{R}(\mu \mathrm{m}) \\
\text { using water }\end{array}$ \\
\hline $\mathrm{C}_{1}$ & 0.75 & $4.15 \times 10^{-14}$ & $7.97 \times 10^{-14}$ & 0.58 & 0.80 \\
\hline $\mathrm{C}_{2}$ & 0.80 & $5.81 \times 10^{-14}$ & $1.10 \times 10^{-13}$ & 0.68 & 0.94 \\
\hline $\mathrm{C}_{3}$ & 0.73 & $3.41 \times 10^{-14}$ & $6.41 \times 10^{-14}$ & 0.52 & 0.72 \\
\hline $\mathrm{C}_{4}$ & 0.76 & $4.45 \times 10^{-14}$ & $8.32 \times 10^{-14}$ & 0.60 & 0.82 \\
\hline
\end{tabular}

Furthermore, it is observed that the ethylene glycol dimethacrylate (EDMA) crosslinker content plays a more predominant role than the 2-ethylhexyl methacrylate monomer content regarding the porosity, permeability and column performance. This effect is clearly observed when comparing the $\mathrm{C}_{3}$ and $\mathrm{C}_{4}$ columns.

To evaluate the mechanical stability and permeability of the monolithic materials, acetonitrile and water eluents were used to measure the pressure drop across the columns at different flow rates. Fig. 1 shows the effect of the flow rate through each column on the backpressure using both eluents. An excellent linear dependence of the four columns inlet pressure
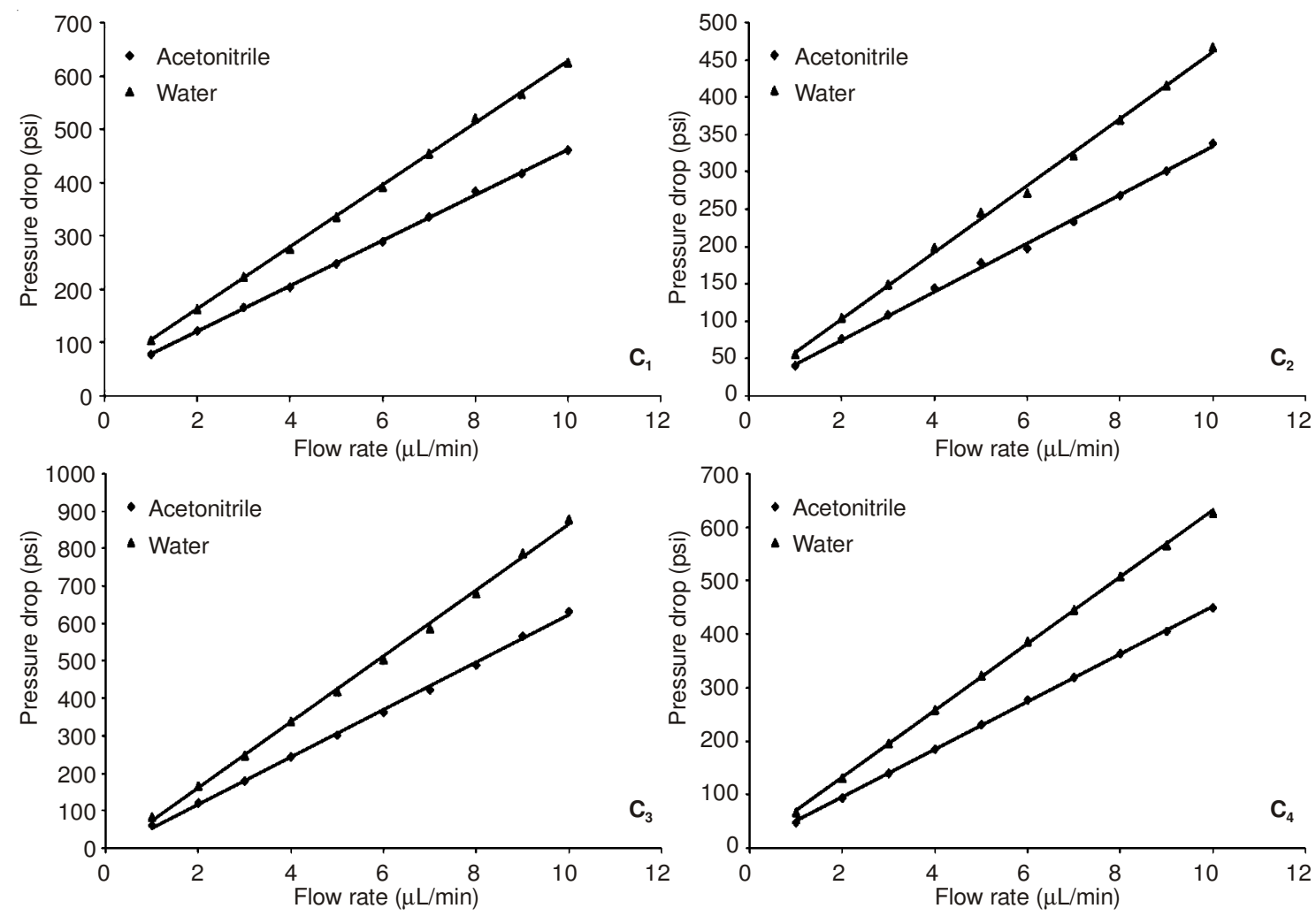

Fig. 1. Graph illustrating the pressure drop versus flow velocity in the $C_{1}, C_{2}, C_{3}$ and $C_{4}$ columns at room temperature 
on the flow rate is indicated by a regression factor better than 0.997 for all measured curves.

While acetonitrile and water were passed through the columns at a volumetric flow rate of $5 \mu \mathrm{L} \mathrm{min}{ }^{-1}$, the permeability values and the average diameter of the monolith channels were determined using pressure drops. The determined values are presented in Table-2. The permeabilities with water are higher than with acetonitrile in all cases. The calculated values indicate that some swelling of the stationary phase occurs with acetonitrile, which causes a restriction of the accessible pore volume. The values confirm that increasing the porogen ratio induced larger macropores while the total porosity and permeability increased.

Monolithic column morphology: The prepared monoliths were analyzed using SEM and FT-IR spectroscopy. Representative SEM images of the $C_{1}$ and $C_{2}$ columns are shown in Fig. 2. The images demonstrate that the synthesis procedure produces permeable monoliths that have a continuous bed, homogeneous structure and porosity, close to the capillary walls. As shown in the figures, the formed monoliths were well attached to the inner surface of the capillaries. The crosssection of the intact and homogeneous columns bed can also be seen in Fig. 2a, b. The microglobules that appear in the figures have an approximate diameter of 1-2 $\mu \mathrm{m}$. Furthermore, the macropore diameters estimated from the SEM images (Fig. 2) are in good agreement with the calculated values given in Table-2.
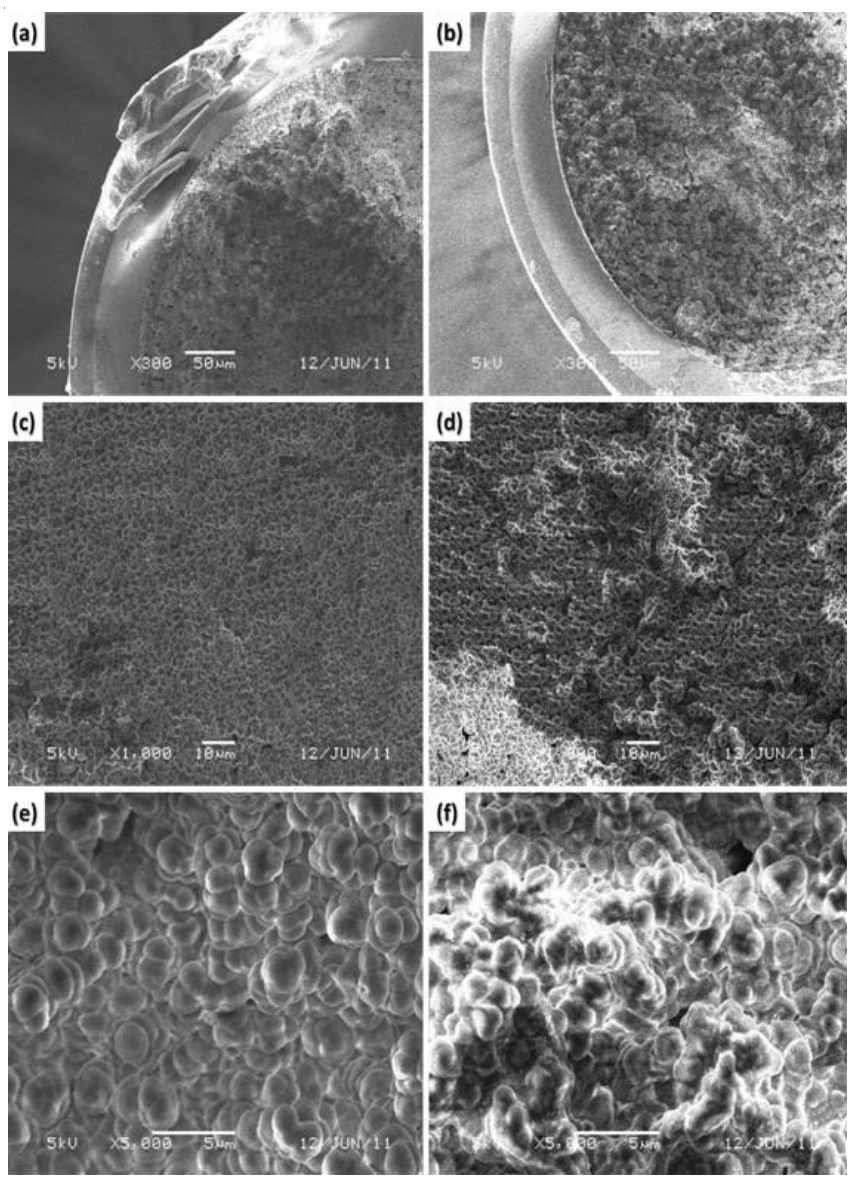

Fig. 2. (a, b) Cross-sectional and (c, d, e, f) bulk region SEM images of the $\mathrm{C}_{1}$ and $\mathrm{C}_{2}$ columns (with different magnifications)
The monoliths were also examined using FT-IR spectroscopy to identify the organic functional groups of the polymeric phase. Fig. 3 shows the presence of the main bands corresponding to the ester functional group of the methacrylate (1733 and $1165 \mathrm{~cm}^{-1}$ ) and the methyl and methylene groups of the alkyl substituents. Furthermore, the absence of stretching bands at 1650 and $3090 \mathrm{~cm}^{-1}$, which correspond to $\mathrm{C}-\mathrm{C}$ and $-\mathrm{C}-\mathrm{H}$ bonds, confirms the completion of the polymerization reaction.

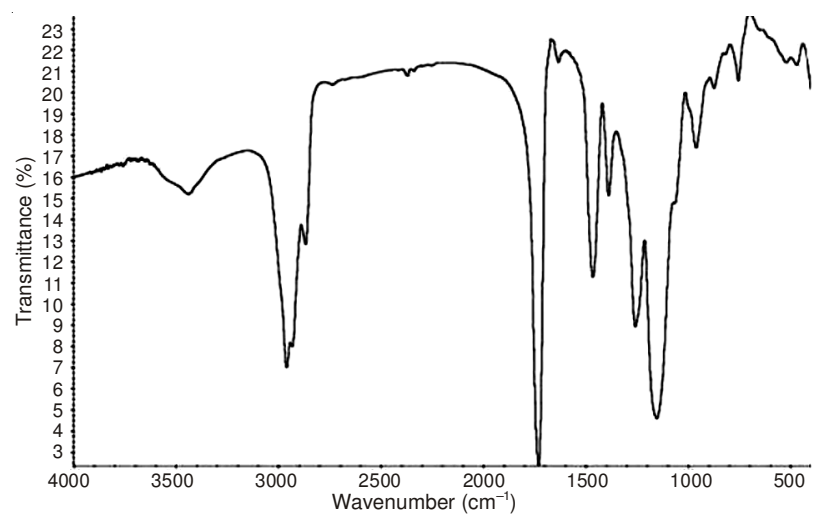

Fig. 3. Infrared spectrum of the monolithic stationary phase

Separation and efficiency of monolithic columns: The efficiencies of the prepared columns were calculated at room temperature and the van Deemter curve was plotted. The number of theoretical plates was studied in all cases for each column. The sample injection volume used with the splitting mode was $5 \mathrm{~nL}$.

Separation of aromatic compounds: The prepared capillary columns were tested for the separation of an aromatics mixture (toluene, nitrotoluene and chlorotoluene) using a binary acetonitrile/water (50:50, v/v \%) at different flow rates. Fig. 4a shows the separation of the three components on the $\mathrm{C}_{1}$ column at flow rates of 30 and $60 \mu \mathrm{L} / \mathrm{min}$ in less than 8 and $4.5 \mathrm{~min}$, respectively. The detection wavelength was set at $260 \mathrm{~nm}$.

The plate height $(\mathrm{H})$ was then calculated for each constituent at different flow rates. The corresponding van Deemter curves are shown in Fig. 5a-c. For the three aromatic compounds, the height equivalent to a theoretical plate remains almost constant in the investigated flow rate range, which was $25-60 \mu \mathrm{L} / \mathrm{min}$. This fact indicates that the column performance is slightly affected by increasing the mobile phase velocity in this range, as it has been previously established for capillary columns in both liquid and gas chromatography ${ }^{39-42}$. Because the plate number remains constant while increasing the flow rate, the capillary columns allow faster analysis without reducing their separation ability.

The fastest separation for the three compounds was achieved in approximately 4 min using the $C_{2}$ column at a flow rate of $60 \mu \mathrm{L} / \mathrm{min}$. The best performance was obtained for toluene at a flow rate of $25 \mu \mathrm{L} / \mathrm{min}$, which corresponded to a column efficiency of 2930 plates $/ \mathrm{m}$.

Separation of phenolic compounds: The prepared capillary columns were also used to separate a mixture of phenolic compounds using different experimental conditions. Fig. $4 \mathrm{~b}$ shows the chromatograms obtained with aminophenol, cresol 

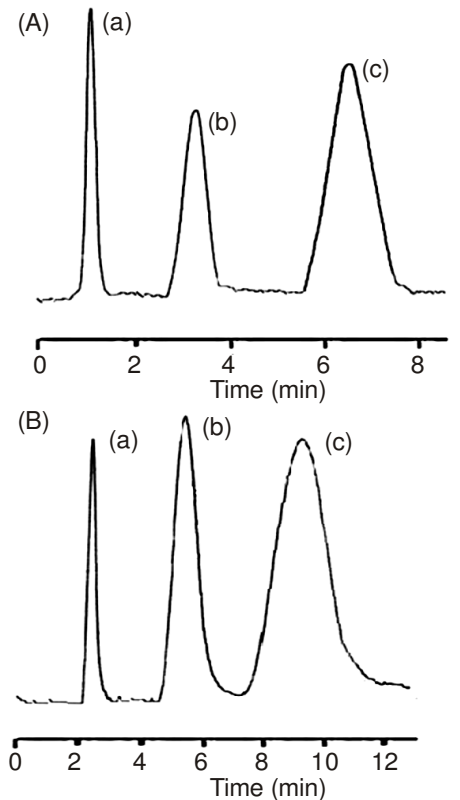
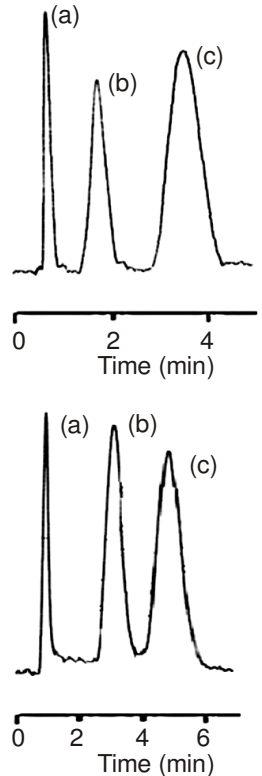

Fig. 4. (A) Chromatograms of the separation of aromatic compounds at different mobile phase flow rates, (left) at 30 and (right) at $60 \mu \mathrm{L} / \mathrm{min}$ using the $\mathrm{C}_{1}$ column, where: (a) toluene, (b) nitrotoluene and (c) chlorotoluene. (B): Chromatograms of the separation of aromatic compounds at different mobile phase flow rates, (left) at 15 and (right) at $30 \mu \mathrm{L} /$ min using the $\mathrm{C}_{1}$ column, where (a) aminophenol, (b) cresol and (c) chlorophenol
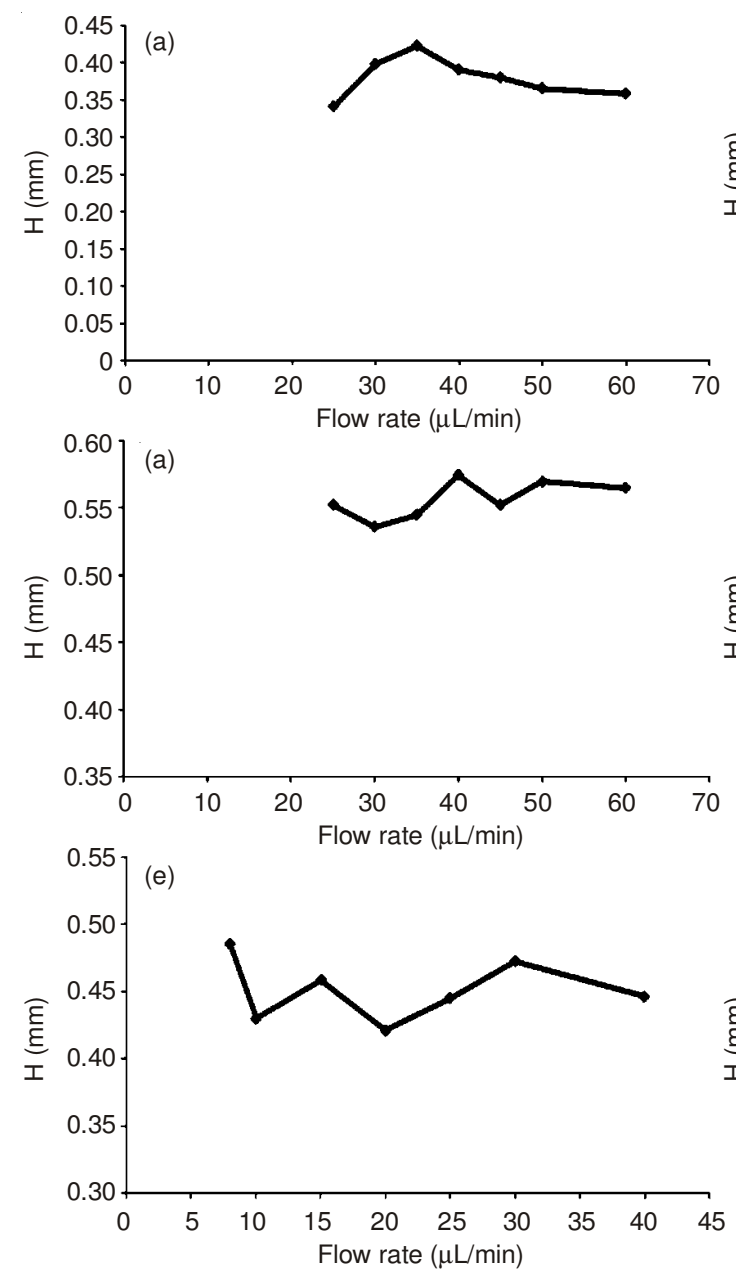

and chlorophenol injected on the $\mathrm{C}_{1}$ column using acetonitrile/ water (40:60, v/v \%) with $1 \%$ formic acid as the mobile phase. The three phenols are completely separated in less than 12 min at a flow rate of $15 \mu \mathrm{L} / \mathrm{min}$ and in less than 6 min at a flow rate of $30 \mu \mathrm{L} / \mathrm{min}$. The detection wavelength was $254 \mathrm{~nm}$.

By varying the mobile phase flow rate, the efficiency of the columns was calculated for each compound. Fig. 5e-g show the van Deemter curves for the three compounds. The best performance was obtained for aminophenol at a flow rate of $20 \mu \mathrm{L} / \mathrm{min}$, which corresponded to a column efficiency of 2415 plates $/ \mathrm{m}$. Again, the plate number fluctuates slightly when the flow rate is increased in the studied range $(8-40 \mu \mathrm{L} / \mathrm{min})$, which indicates that the separation ability of the column is not significantly affected by using a higher mobile phase velocity.

All of these results indicate that capillary monolithic columns could be an interesting and economic alternative to conventional columns for the separation and determination of priority pollutants, such as polycyclic aromatic hydrocarbons.

\section{Conclusion}

Four monolithic capillary columns were prepared using a single step in situ free radical polymerization of 2-ethylhexyl methacrylate in fused silica tubing with different compositions. The procedure proved to be rapid, simple and efficient; it required only small quantities of solvents and reagents. The prepared monoliths were characterized by SEM and FT-IR. Their porosity
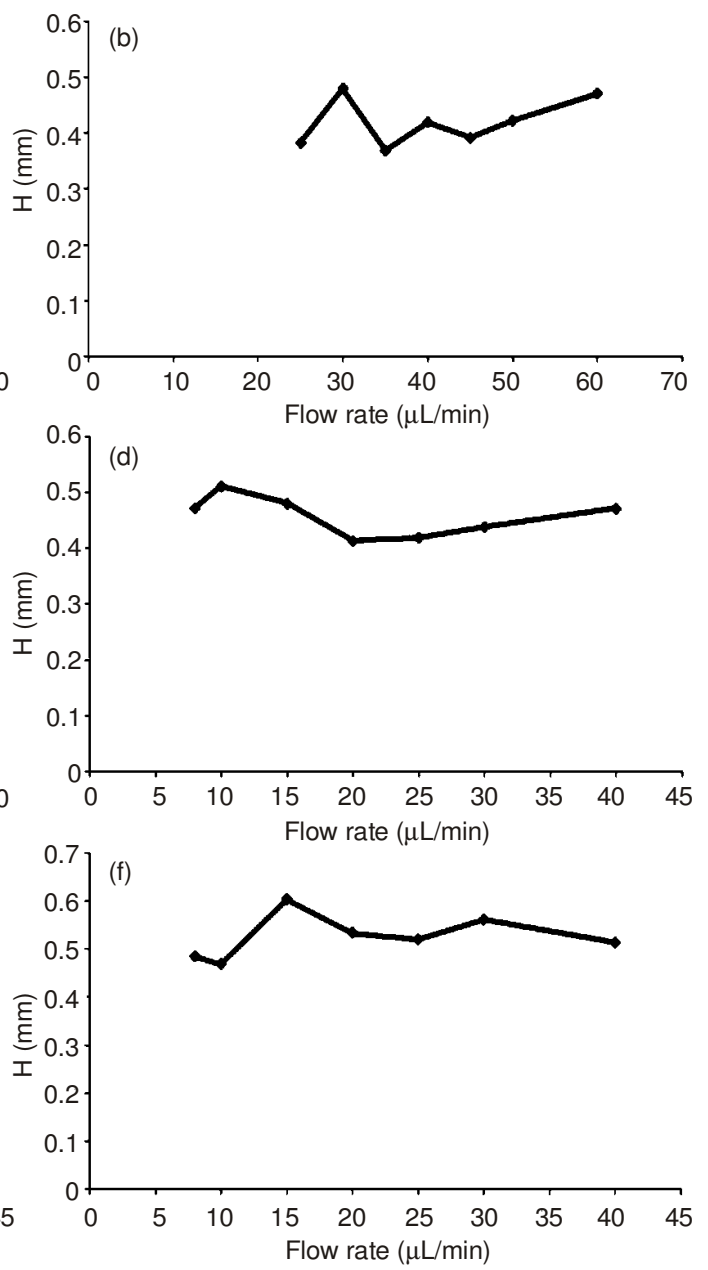

Fig. 5. Van Deemter plot of the height equivalent to a theoretical plate as a function of flow rate for (a) toluene, (b) nitrotoluene, (c) chlorotoluene, (d) aminophenol (e) cresol and (f) chlorophenol compounds 
and permeability were also determined and compared with the morphology parameters obtained from the micrographs. The capillary columns were also successfully applied to separate different types of compound, such as aromatic hydrocarbons and phenols, with sufficient separation efficiency.

\section{ACKNOWLEDGEMENTS}

This project was supported by King Saud University, Deanship of Scientific Research, College of Science Research Center.

\section{REFERENCES}

1. C. Gu, J. He, J. Jia, N. Fang, R. Simmons and S.A. Shamsi, J. Chromatogr. A, 1217, 530 (2010).

2. Y. Song and Y.M. Liu, J. Mass Spectrom., 43, 1285 (2008).

3. L. Tastet, D. Schaumloffel, B. Bouyssiere and R. Lobinski, Talanta, 75, 1140 (2008).

4. M.I. Bailón-Pérez, A.M. García-Campaña, M. del Olmo-Iruela, L. GámizGracia and C. Cruces-Blanco, J. Chromatogr. A, 1216, 8355 (2009).

5. M. Petrovic, M. Farré, M.L. de Alda, S. Perez, C. Postigo, M. Köck, J. Radjenovic, M. Gros and D. Barcelo, J. Chromatogr. A, 1217, 4004 (2010).

6. D. Lubda and W. Lindner, J. Chromatogr. A, 1036, 135 (2004).

7. K. Qian, T. Tang, T. Shi, F. Wang, J. Li and Y. Cao, Anal. Chim. Acta, 635, 222 (2009).

8. H.J. Issaq, K.C. Chan, J. Blonder, X. Ye and T.D. Veenstra, J. Chromatogr. A, 1216, 1825 (2009).

9. G. D'Orazio, A. Cifuentes and S. Fanali, Food Chem., 108, 1114 (2008).

10. M. Dakna, Z. He, W. Yu, C.H. Mischak and W. Kolch, J. Chromatogr. $B, 877,1250$ (2009).

11. K.K. Unger, R. Skudas and M.M. Schulte, J. Chromatogr. A, 1184 393 (2008)

12. R. Wu, L. Hu, F. Wang, M. Ye and H. Zou, J. Chromatogr. A, 1184, 369 (2008).

13. B. Buszewski and M. Szumski, Chromatographia, 60(S1), S261 (2004)

14. C. Yang, T. Ikegami, T. Hara and N. Tanaka, J. Chromatogr. A, 1130, 175 (2006).

15. S. Hjertén, J.L. Liao and R. Zhang, J. Chromatogr. A, 473, 273 (1989).

16. F. Svec and J.M.J. Frechet, Anal. Chem., 64, 820 (1992).

17. H. Minakuchi, K. Nakanishi, N. Soga, N. Ishizuka and N. Tanaka, Anal. Chem., 68, 3498 (1996).

18. P. Coufal, M. Cihak, J. Suchankova, E. Tesarova, Z. Bosakova and K. Stulík, J. Chromatogr. A, 946, 99 (2002).

19. P. Holdšvendová, P. Coufal, J. Suchánková, E. Tesarová and Z. Bosáková, J. Sep. Sci., 26, 1623 (2003).

20. J. Grafnetter, P. Coufal, E. Tesarova, J. Suchankova, Z. Bosakova and J. Sevcik, J. Chromatogr. A, 1049, 43 (2004).
21. X.L. Dong, R. Wu, J. Dong, M.H. Wu, Y. Zhu and H.F. Zou, Electrophoresis, 29, 919 (2008).

22. P. Sirc, Z. Bosáková, P. Coufal, J. Michálek and V. Guryca, Mater. Manuf. Process., 23, 591 (2008).

23. E.G. Vlakh and T.B. Tennikova, J. Chromatogr. A, 1216, 2637 (2009).

24. O. Kornysova, A. Maruska, P.K. Owens and M. Erickson, J. Chromatogr. A, 1071, 171 (2005).

25. Y. Ueki, T. Umemura, Y. Iwashita, T. Odake, H. Haraguchi and K. Tsunoda, J. Chromatogr. A, 1106, 106 (2006).

26. Z. Jiang, N.W. Smith, P.D. Ferguson and M.R. Taylor, J. Biochem. Biophys. Methods, 70, 39 (2007).

27. B. Schlemmer, R. Bandari, L. Rosenkranz and M.R. Buchmeiser, J. Chromatogr. A, 1216, 2664 (2009).

28. K. Mistry and N. Grinberg, J. Liq. Chromatogr. Rel. Technol., 28, 1055 (2005).

29. Y. Li, J. Zhang, R. Xiang, Y. Yang and C. Horvath, J. Sep. Sci., 27, 1467 (2004).

30. F. Svec, J. Chromatogr. A, 1217, 902 (2010).

31. D. Moravcova, P. Jandera, J. Urban and J. Planeta, J. Sep. Sci., 26, 1005 (2003).

32. X. Shu, L. Chen, B. Yang and Y. Guan, J. Chromatogr. A, 1052, 205 (2004).

33. H. Oberacher, A. Premstaller and C.G. Huber, J. Chromatogr. A, 1030, 201 (2004).

34. S.H. Lubbad and M.R. Buchmeiser, J. Chromatogr. A, 1217, 3223 (2010).

35. L. Cong, B. Huang, Q. Chen, B. Lu, J. Zhang and Y. Ren, Anal. Chim. Acta, 569, 157 (2006).

36. Z. Jiang, J. Reilly, B. Everatt and N.W. Smith, J. Chromatogr. A, 1216, 2439 (2009).

37. D. Cabooter, F. Lynen, P. Sandra and G. Desmet, J. Chromatogr. A, 1157, 131 (2007)

38. Z.A. ALOthman, A. Aqel, H.A. Al Abdelmoneim, A. Yacine Badjah-HadjAhmed and A.A. Al-Warthan, Chromatographia, 74, 1 (2011).

39. G. Guiochon, J. Chromatogr. A, 1168, 101 (2007).

40. M. Dresselhaus, G. Dresselhaus, R. Saito and A. Jorio, Phys. Rep., 409, 47 (2005).

41. A. Jorio, M. Pimenta, C. Fantini, M. Souza, A. Souza Filho, G. Samsonidze, G. Dresselhaus, M. Dresselhaus and R. Saito, Carbon, 42, 1067 (2004).

42. J. Lefebvre, J. Fraser, Y. Homma and P. Finnie, Appl. Phys., A Mater. Sci. Process., 78, 1107 (2004).

43. C.S. Horvath and H.J. Lin, J. Chromatogr. A, 126, 401 (1976).

44. J. Bear, Dynamics of Fluids in Porous Media, Dover Publications, New York, p. 113 (1988)

45. K.K. Unger, Porous Silica, its Properties and Use as Support in Columns Liquid Chromatography, Elsevier, Amsterdam, p. 171 (1979).

46. V.M. Meyers, Practical High-Performance Liquid Chromatography, Wiley, New Jersey (2005).

47. M. Zabka, M. Minceva and A.E. Rodrigues, J. Biochem. Biophys. Methods, 70, 95 (2007). 